Lecturer, go my thanks for obtaining much of the literature on the subject. To Miss Shirley Moss for the typescript, and to my wife for her tolerance and patience during the paper's preparation goes my sincere gratitude.

\section{Summary}

A brief résumé of the early history of the operation of tracheostomy is given in which is pointed out the strong difference of opinion among the earlier physicians in regard to the value of the operation: tracheostomy being originally an operation conceived on a purely mechanical basis as a means of short-circuiting entry of air into the lower airway by bypassing the larynx. Reference is also made to the upset in blood chemistry from prolonged oxygen want and the risk of fatal apnoea after the successful performance of a tracheostomy in such cases.

Starting with the observations of Montgomery in 1885 and reinforced by the work of Galloway in 1943, a better appreciation and wider application of tracheostomy begins to develop.
The work of Galloway is contained in his report on the ". Benefits of Tracheostomy in Poliomyelitis." The recognition by Professor Lassen, of Copenhagen, that poliomyelitis deaths were due principally to deficient ventilation and ventilatory failure formed the real basis of the modern application of the use of tracheostomy in a wide variety of conditions.

The article then explains the basic factors of respiration and goes on to outline the applications of the principles, resulting from Professor Lassen's observations, in conditions varying from severe head injuries, severe injuries to the chest, and ventilatory failure resulting from diseases of the chest.

BIBLIOGRAPHY

Galloway, T. C. (1943). f. Amer. med. Ass., 123, 1096

Kodicek, J. M. (1960). \%. Laryng., 74, 891.

Lassen, A. C. A. (1953). Lancet, 1, 37

Montgomery, E. E. (1885). Arch. Pediat., 2, 577. (Reprinted in Arch. Pediat., 1944, 61, 489.)

Nelson, T. G. (1958). Tracheostomy-Clinical Experimental Study. Williams and Wilkins, Baltimore.

Spalding, J. M. K., and Smith, A. C. (1963). Clinical Practice and Physiology of Artificial Respiration. Blackwell, Oxford.

\title{
Present Treatment of Schizophrenia-a Controlled Follow-up Study
}

\author{
D. H. W. KELLY,* M.B., M.R.C.P., D.P.M. ; WILLIAM SARGANT,* M.B., F.R.C.P., D.P.M.
}

Brit. med. F., 1965, 1, 147-150

The treatment of schizophrenia has undergone revolutionary changes for the better during the past 30 years, largely because of the discovery of new physical methods of treatment. Before their introduction, Guttmann, Mayer-Gross, and Slater (1939) investigated 188 specially selected schizophrenics who had had treatment at the Maudsley Hospital in 1934 and 1935. Only patients under 46 who were having their first breakdown and had an apparent history of less than one year's duration were considered. The average length of hospital stay, however, was still 4.6 months, and no less than $41 \%$ were in hospital when followed up three years later. Insulin coma (Sakel, 1935) and convulsive treatment (Meduna, 1935) were then introduced, and Hoenig, Leiberman, and Auerbach (1956), comparing the results of a group of schizophrenics treated with insulin coma and E.C.T. (1948-50) with a comparable group (1934-5) treated before their introduction, found that $68 \%$ of the "treated" group improved, compared with only $35 \%$ of the "control" group. To find out whether insulin was the specific therapeutic agent in the treatment of schizophrenia Ackner, Harris, and Oldham (1957) compared the results of insulin and of a deep barbiturate-induced coma on matched pairs of patients. They concluded that insulin was not the specific therapeutic agent, although the coma regimen might explain its value. In fact, prolonged sleep treatment has been extensively used in Russia, and the results, although not as spectacular, compare favourably with those of insulin coma (Ivanov-Smolenskii, 1939). It is interesting that Ackner's patients gained a lot of weight during treatment, as do insulin-treated and sleep-treated patients.

The introduction of phenothiazines was the next major advance in treatment. To find out the advantages of using chlorpromazine, E.C.T., and insulin subcoma, rather than full coma and E.C.T., Rohde and Sargant (1961) reported the results of two groups of schizophrenics treated at St. Thomas's Hospital, before and after the introduction of chlorpromazine

\footnotetext{
* From the Department of Psychological Medicine, St. Thomas's Hospital, London.
}

in 1956. They found that the length of stay in hospital had fallen from 10.7 to only 6.3 weeks, and that the " phenothiazinetreated" patients showed a significant advantage over the " insulin-coma-treated" patients, when followed up two years later. The change in prognosis seemed so great, amounting to a treatment revolution, especially in the earlier cases of this dreaded illness ; and so we felt it most important to follow up a further similar group, to see if these favourable treatment results were confirmed by it or not.

\section{Present Series}

The present investigation is a follow-up study of 48 more patients suffering from schizophrenia who were treated in the psychiatric in-patient unit between 1960 and 1963. They were practically all diagnosed and selected by one of us (W.S.) as likely to benefit from intensive treatment, and were fully discussed at the weekly case conferences. Their average age was 29.6 years; 20 were male and 28 female. The average length of time since the onset of symptoms suggestive of schizophrenia was three years and four months, so by no means all were early patients; but most still seemed treatable. The average duration of the present attack was, however, only 12.1 months. Twenty (42\%) had had previous in-patient treatment. Only patients who were admitted to our unit for the first time were included in this series, because those patients who had previously been admitted formed part of the earlier series (Rohde and Sargant, 1961).

\section{Treatment 1960-3}

The patients were treated in a pleasant general hospital psychiatric unit of 20 beds, mostly in single and double rooms. This is situated in the Royal Waterloo Hospital, which became part of St. Thomas's Hospital at the start of the National 
Health Service. The nursing staff consisted usually of only one psychiatrically trained sister; the rest of the nurses were all undergoing their general training at St. Thomas's. There were no locked doors of any sort, and the patients, when well enough, were able to go out freely, and to $\mathrm{mix}$ with others from the medical and surgical wards in the occupational therapy department.

All the patients were treated with phenothiazines, and 40 $(83 \%)$ were treated with a daily dose of more than $300 \mathrm{mg}$. of chlorpromazine, or equivalent dose of phenothiazine. With large doses of phenothiazines E.C.T. was also given as soon as possible after admission and, if thought desirable, modified narcosis. It was found that even the most acutely disturbed schizophrenic patient could thus be brought rapidly under control and so nursed in general hospital surroundings.

Forty-four (92\%) were treated with E.C.T., which was generally given twice weekly at first, unless the patient was very disturbed; and later once weekly with a fresh assessment before each treatment. The average number of E.C.T.s was 6.3 (range 2-22). Only two patients $(4 \%$ ) had insulin coma, but many were underweight at the time of admission, and modified insulin-that is, a small dose sufficient to induce drowsiness and stimulate the appetite-was used in 23 patients (48\%).

Antidepressants were also found to be valuable in selected cases, and were given to 17 patients $(35 \%)$. They were found to be particularly valuable in overcoming the anergia and lethargy characteristic of the recovery phase of the illness and often accentuated by phenothiazines. Care was taken, however, to ensure that manic excitement, with a return of schizophrenic symptomatology, was not induced.

\section{Results Obtained}

Table I shows the methods of treatment used and the change in the pattern of treatment in this unit during the past 13 years. The average length of stay was still only 6.7 weeks (see Table II). Before final discharge the patients were gerrerally sent home for week-ends to ensure that they were able to cope with the home environment. Only four patients $(8 \%)$ had to be transferred to mental hospitals-two for rehabilitation and two under Section 26 of the Mental Health Act as a matter of urgency. This in itself constituted a startling change from the period when insulin coma and E.C.T. were used alone.

At the time of discharge a clinical assessment was made and patients were rated according to their social and psychiatric states (after Ackner et al., 1957). Social status: (1) independent, if the patient was or is able to work and support himself, or in the case of a housewife to run her home ; 2 dependent, if out of hospital, but unable to support himself or run a home; and (3) institutional, if in hospital or nursing-home. Psychiatric state: (a) symptom-free and apparently recovered; (b) residual symptoms, no evidence of active schizophrenia but

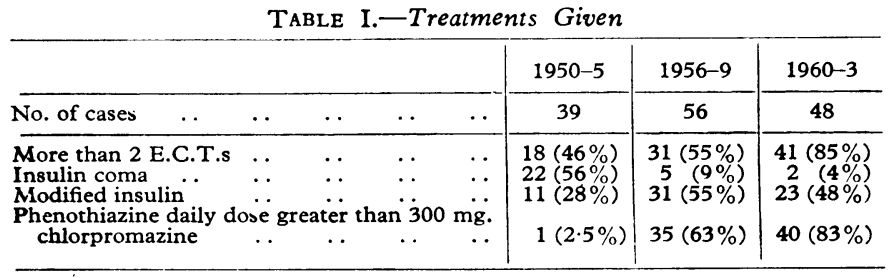

TABLE II.-Duration of Stay and Transfers

\begin{tabular}{|c|c|c|c|c|c|}
\hline & & & $1950-5$ & $1956-9$ & $1960-3$ \\
\hline Schizophrenics admitted & $\ldots$ & $\ldots$ & 39 & 56 & 48 \\
\hline $\begin{array}{l}\text { Average duration of stay } \\
\text { Transferred to mental hospitals } \\
\text { Transferred urgently . . .. }\end{array}$ & $\begin{array}{l}\ldots \\
\cdots\end{array}$ & $\begin{array}{l}\cdots \\
\cdots\end{array}$ & $\begin{array}{c}10 \cdot 7 \text { weeks } \\
12(31 \%) \\
3(8 \%)\end{array}$ & $\begin{array}{c}6.3 \text { weeks } \\
5(9 \%) \\
1(2 \%)\end{array}$ & $\begin{array}{c}6.7 \text { weeks } \\
4(8 \%) \\
2(4 \%)\end{array}$ \\
\hline
\end{tabular}

some deterioration compared with pre-morbid personalitynamely, flattening of affect, depression, or deterioration in work efficiency ; and (c) psychotic, evidence of active schizophrenia.

All 48 patients have been followed up, and $81 \%$ interviewed personally by one of us (D. H. W. K.). In the remaining $19 \%$ an assessment was based on a questionary and letters from the patient, his nearest relative, or his practitioner. The mean time between discharge from hospital and follow-up was two years and one month.

The assessment at the time of follow-up is shown in Table III. No less than $92 \%$ of patients were found to be out of hospital at the time of follow-up, although $20(42 \%)$ had had further, mostly short, periods of in-patient treatment during the follow-up period. Fifteen (31\%) had been readmitted once, and five $(10 \%)$ had been readmitted twice. The average duration of each readmission was, however, still only 9.8 weeks. Thirty-eight patients (79\%) should have been taking phenothiazines: $30(62 \%)$ were taking their tablets regularly, $8(17 \%)$ were not doing do. Three patients, only $6 \%$ of the whole, had leucotomies during the follow-up period, but all of them were still rated as psychotic at the time of follow-up.

\begin{tabular}{|c|c|c|c|}
\hline & & Discharge State & Follow-up \\
\hline Social status & $\ldots\left\{\begin{array}{l}\text { Independent } \\
\text { Dependent } \\
\text { Institutional } \ldots\end{array}\right.$ & $\begin{array}{l}36(75 \%) \\
8(17 \%) \\
4(8 \%)\end{array}$ & $\begin{array}{l}32(67 \%) \\
12(25 \%) \\
4(8 \%)\end{array}$ \\
\hline Psychiatric state & $\left\{\begin{array}{l}\text { Symptom-free } \\
\text { Residual symptoms } \\
\text { Psychotic } \ldots\end{array} \ldots\right.$ & $\begin{array}{r}19(40 \%) \\
22(46 \%) \\
7(14 \%)\end{array}$ & $\begin{array}{l}23(48 \%) \\
13(27 \%) \\
12(25 \%)\end{array}$ \\
\hline
\end{tabular}

\section{Two-year Follow-up Study}

This study was designed to determine the actual state of patients two years after discharge from hospital. It is only by this means that different periods of follow-up can be equated, so that a direct comparison can be made between those who were treated before and those who were treated after the introduction of phenothiazines in 1956. Two groups of 39 patients treated during $1950-5$ and 1956 to August 1958 have been previously reported (Rohde and Sargant, 1961). The results showed a statistically significant improvement in the " phenothiazine-treated" group. Forty-five patients discharged between September 1958 and 31 December 1961 have now also been followed up, and an assessment has been made of their condition two years after leaving hospital. Only one patient could not be traced, and she was therefore graded as an institutional psychotic. The results from the recent study (Table IV), although not quite as good as those obtained from the 1956-8 group, are not very much inferior, and still show a marked improvement over the 1950-5 group, who were treated predominantly with insulin coma. Table $\mathrm{V}$ shows the results obtained when the 39 patients treated predominantly with insulin coma in 1950-5 are compared with the 84 patients treated with phenothiazines in $1956-61$ and assessed after a similar period of follow-up.

The most striking feature about these results is that prior to the introduction of phenothiazines $31 \%$ of the schizo-

Table IV.-State of Patients Two Years After Discharge

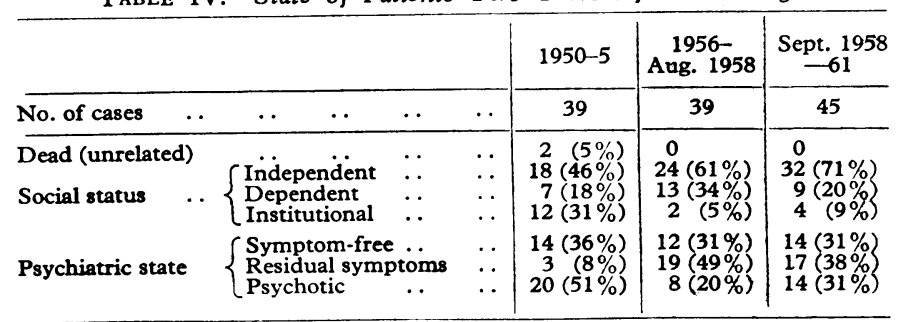


Table V.-Stoze of Patients Two Years After Discharge Before and After the Introduction of Phenothiazines

\begin{tabular}{|c|c|c|c|c|c|c|c|c|}
\hline \multirow[b]{2}{*}{ No. of cases .. } & \multirow[b]{2}{*}{.. } & \multirow[b]{2}{*}{.. } & \multirow[b]{2}{*}{.. } & \multirow[b]{2}{*}{$\cdots$} & \multirow{2}{*}{$\begin{array}{c}\begin{array}{c}1950-5 \\
\text { Insulin } \\
\text { Coma } \\
\text { Main } \\
\text { Form of } \\
\text { Treatment }\end{array} \\
39 \\
\end{array}$} & \multirow{2}{*}{$\begin{array}{c}\begin{array}{c}1956-61 \\
\text { Pheno- } \\
\text { thiazine- } \\
\text { treated } \\
\text { Group }\end{array} \\
84\end{array}$} & \multicolumn{2}{|c|}{$\begin{array}{c}\text { Test of } \\
\text { Significance }\end{array}$} \\
\hline & & & & & & & $x^{2}$ & $\mathbf{P}$ \\
\hline $\begin{array}{l}\text { Dead (unrelated) } \\
\text { Social status .. }\end{array}$ & $\left\{\begin{array}{l}\text { Ind } \\
\text { De } \\
\text { Ins }\end{array}\right.$ & $\begin{array}{l}\text { Dendent } \\
\text { ndent } \\
\text { utional }\end{array}$ & $\because$ & $\begin{array}{l}\because \\
\because \\
\cdots\end{array}$ & $\begin{array}{r}2(5 \%) \\
18(46 \%) \\
7(18 \%) \\
12(31 \%)\end{array}$ & $\begin{array}{c}0 \\
56(67 \%) \\
22(26 \%) \\
6(7 \%)\end{array}$ & $\begin{array}{c}3.51 \\
1.2 \\
11 \cdot 1\end{array}$ & $\begin{array}{l}\text { N.S. } \\
\text { N.S. } \\
0.001\end{array}$ \\
\hline Psychiatric State & $\left\{\begin{array}{l}\text { Syr } \\
\text { Res } \\
\text { Psy }\end{array}\right.$ & $\begin{array}{l}\text { lual sym } \\
\text { lotic }\end{array}$ & eptoms & $\begin{array}{l}\ldots \\
\because \\
\cdots\end{array}$ & $\begin{array}{r}14(36 \%) \\
3(8 \%) \\
20(51 \%)\end{array}$ & $\begin{array}{l}26(31 \%) \\
36(43 \%) \\
22(26 \%)\end{array}$ & $\begin{array}{r}0.55 \\
12.66 \\
8.82\end{array}$ & $\begin{array}{l}\text { N.S. } \\
0.001 \\
0.005\end{array}$ \\
\hline
\end{tabular}

phrenics treated in 1950-5 were in hospital when followed up two years later; and no less than $51 \%$ were rated at that time as psychotic. Since the introduction of phenothiazines and the adoption of the new physical treatment regimen, in exactly the same environment, only a mere $7 \%$ are in hospital and only $26 \%$ are rated as psychotic after a similar period of follow-up. The length of stay in hospital for the key admissions had also fallen from 10.7 weeks to only 6.7 weeks.

\section{Discussion}

The treatment of schizophrenia in this unit has changed radically over the past 13 years, while the methods of diagnosis and selection, and the general treatment setting have remained fairly constant. Insulin coma, which used to be employed in the treatment of $56 \%$ of schizophrenic patients, is now used in only $4 \%$. Phenothiazines in a daily dosage greater than $300 \mathrm{mg}$. of chlorpromazine had been used in only $2.5 \%$ of cases before 1956 , but are now used in $83 \%$ of cases. The number of patients receiving E.C.T. has also risen from $46 \%$ to $85 \%$; the average number now employed is six.

That the present treatment is far superior is clearly shown by the follow-up results. Before 1956 no less than $51 \%$ of selected schizophrenics were psychotic, and $31 \%$ were in hospital two years after discharge. Since the introduction of phenothiazines and the use of more E.C.T., of the 84 patients treated during 1956-61, only $26 \%$ were still thought to be psychotic and a mere $7 \%$ were in hospital after a similar period of follow-up. These results are so striking that we must consider various factors which, although not directly related to treatment methods, might in fact be responsible for this. It is possible that the improved results are due to better methods of selection. The cases were mostly diagnosed and selected by one of us (W. S.), who had been selecting special patients for admission to the Maudsley and elsewhere ever since 1936. The criteria for diagnosis have not been changed over the past 13 years. It is unlikely that the ability to select only those cases which would ultimately do well should now be present in somebody who prior to 1956 did not then have this ability. The cases now admitted are no less severe than those selected before the introduction of phenothiazines; indeed, the reverse is the case, since more acutely disturbed patients, who could not be treated under general hospital conditions when insulin coma was the main form of treatment, can now be brought rapidly under control with phenothiazines, E.C.T., and if necessary modified narcosis. As a result of the change in the treatment regimen the number of patients requiring transfer to mental hospitals has fallen from $31 \%$ to only $8 \%$.

It is possible that, by the selection of only really early and acute cases even better results could have been achieved. In fact, in the 1960-3 cohort the average duration of symptoms suggestive of schizophrenia prior to admission was no less than three years and four months; but the mean duration of the present attack was only 12.1 months. Forty-two per cent. of our cases had also had previous in-patient treatment for schizophrenia, mostly in mental hospitáls, and $6 \%$ were sufficiently severe and intractable to require leucotomy subsequently. It is also unlikely that the enthusiasm of the unit in which the patients were treated could be held responsible for the improved results. For even in the pre-phenothiazine era this general hospital teaching unit was one of the first of its kind in the country, and treatment was certainly carried out as enthusiastically and intensively then as it is now. Very little psychotherapy was found necessary, nor generally were any complicated methods of rehabilitation.

Although the improvement with phenothiazines has been remarkable it is interesting to find that the percervage of patients found to be symptom-free at follow-up has not changed significantly since their introduction. The improvement has mainly been confined to a shift from the "psychotic" to the "residual symptom" group. Perhaps our assessment of full recovery has been deliberately too strict. The controlling of psychotic symptomatology has meant, however, that a large percentage of patients who formerly would have had to remain in the chronic wards of mental hospitals can now live and work happily back in the community again.

Together with the phenothiazines, we have still continued to use modified insulin and E.C.T. When progress has been held up we have even given a few insulin sopors, often with helpful results. It is our impression that almost routine additional E.C.T. increases the speed of remission, and gain of weight with modified insulin also seems to help prevent relapse. But undoubtedly it has been the phenothiazines that are mostly responsible for the startling change in treatment prognosis seen in the two recent groups followed up.

Our results, although not directly comparable, are very different from those obtained from a survey of 113 schizophrenic patients who left mental hospitals in London in 1959 (Wing, Monck, Brown, and Carstairs, 1964). The mean length of stay of that series was four months, $56 \%$ had deteriorated in their clinical condition, and $43 \%$ had to be readmitted during the follow-up period of one year. Of our cases treated in 1960-3, and followed up for a mean period of two years and one month, the readmission rate was $42 \%$, and the mean length of stay for the key admission of 6.7 weeks was very much shorter. More intensive treatment, made possible by a higher staff-to-patient ratio, may in part be responsible for this. Only $90 \%$ of mental hospital cases had phenothiazines, which was the sole form of treatment in $48 \%$ of cases. All our cases had phenothiazines, and in only $6 \%$ of them were phenothiazines the sole form of treatment given.

This report therefore confirms the findings of our first follow-up series. It seems that psychiatric units in general hospitals can now treat all but the most severe chronic schizophrenic patients under open-ward conditions, and when more general hospital beds of this sort are made available most schizophrenic patients, who formerly had to be sent to our large mental hospitals, could be treated under general-hospital conditions. The significance of these two follow-up groups confirming each other is of course considerable. After centuries when bleeding, purging, social treatments, and varied forms of psychotherapy were the only forms of treatment available to help these patients and with such bad results, it does now seem that the symptoms of a severe disease, affecting one in every hundred of the population and resulting in the past in so much prolonged chronicity, are on the way to being controlled at last. Further physiological rather than psychological research is, however, still needed to bring about its final cure.

\section{Summary}

The results of a two-year follow-up of 39 schizophrenic patients treated mainly with insulin coma are compared with 84 schizophrenics treated since the introduction of phenothiazines. Of the "insulin-treated" group, $31 \%$ were in hospital and $51 \%$ were rated as psychotic at follow-up, compared 
with $7 \%$ in hospital and $26 \%$ psychotic of the " phenothiazinetreated" group. The methods of selection, the environment, and the general treatment setting were the same for both groups. Very little if any detailed psychotherapy was found necessary, and in only a few cases was special rehabilitation needed. The average length of stay has also been reduced, from 10.7 to 6.7 weeks. The percentage of patients rated as "symptom-free" has not, however, been increased by phenothiazines; the improvement has been confined to a shift from the "psychotic" to the "residual symptom" group, probably in part due to the striktness of our criteria for recovery.

Details are given of the change in the pattern of treatment of schizophrenia in a general hospital psychiatric unit over the past 13 years. It is suggested that a major revolution has occurred in the treatment possibilities of this illness, which can now also be carried out so easily in a general rather than a mental hospital setting. Skilled handling of the physical treatments is most important, with a determination to use every combination of treatments likely to help any individual patient.
Statistical Note.-The probabilities were calculated by chisquare to give some estimate of the differences, but as the original selection was not randomized the tests may not be fully appropriate. We wish to thank Dr. E. D. West for statistical advice on our figures.

We are grateful for a grant of money from Mr. Robert Sainsbury which has made this research possible.

\section{REFERENCES}

Ackner, B., Harris, A., and Oldham, A. J. (1957). Lancet, 1, 607. Guttmann, E., Mayer-Gross, W., and Slater, E. T. O.' (1939). F. Neurol. Neurosurg. Psychiat., $2,25$.

Hoenig, J., Leiberman, D. M., and Auerbach, I. (1956). Ibid., 19, 130. Ivanov-Smolenskii, A. (1939). Sovetsk. Psikhonevr., 15, 16.

Ivanov-Smolenskii, A. (1939). Sovetsk. Psikhonevr., 15, 16.
Meduna, L. (1935). Z. ges. Neurol. Psychiat., 152, 235.

Reduna, L. (1935). Z. ges. Neurol. Psychiat., 152, 235.

Sakel, M.'(1935). Neue Behandlungsmethode der Schizophrenie. Perles, Vienna and Leipzig.

Wing, J. K., Monck, E., Brown, G. W., and Carstairs, G. M. (1964). Brit. f. Psychiat., 110, 10.

\title{
Place of a Double-barrelled Ileostomy in Ulcerative Colitis and Crohn's Disease of the Colon: a Preliminary Report.
}

\author{
S. C. TRUELOVE,* M.D., F.R.C.P.; HAROLD ELLIS, ${ }^{*} \dagger$ D.M., M.CH., F.R.C.S. ; \\ C. U. WEBSTER,* M.B., CH.B., F.R.C.S., F.R.C.S.ED.
}

During the past five years we have been employing a doublebarrelled ileostomy in certain selected cases of ulcerative colitis and Crohn's disease of the colon. In essence, this procedure consists in dividing the ileum about 9 in. $(23 \mathrm{~cm}$.) from the ileocaecal valve, bringing the proximal cut end of ileum to the surface in the right iliac fossa to form a standard ileostomy, and bringing the distal cut end of ileum to the surface in the right hypochondrium. By this means the colon is defunctioned and it is also easy to apply topical therapy, such as corticosteroids, to the entire colon by dripping a solution into the distal ileal stoma. In addition to its allowing efficient application of topical treatment to the colon, conservative surgery can be practised on the isolated colon without the disadvantage of a faecal stream being present. The essential aim has been to see if restoration of the continuity of the gastro-intestinal tract can be performed subsequently without relapse of the disease.

Our object now is to describe the indications we have followed for employing this procedure and to present the results obtained up to the present time. Surgical technicalities are not dealt with, as they will be covered in detail in a separate article.

\section{Indications}

Our indications for double-barrelled ileostomy have been (1) severe disease failing to respond to a full medical regime; (2) chronic disease associated with local bowel complications, such as stricture, entero-enteric fistula, or perianal complications such as recto-vaginal fistula or severe fistula-in-ano ; and (3) chronic disease in childhood associated with failure of normal development.

* From the Radcliffe Infirmary, Oxford.

t Now Professor of Surgery, Westminster Hospital Medical School, London.
It will be appreciated that the orthodox treatment for all three of these categories is total colectomy with permanent ileostomy, although some would be suitable for the less orthodox procedure of subtotal colectomy with ileo-rectal anastomosis as employed by Aylett (1959).

\section{Results}

Thirty-one cases have been treated with double-barrelled ileostomy, the results being summarized in Tables I and II. We here describe some of the problems associated with our three indications for this procedure together with illustrative examples from each group.

\section{Severe Disease Failing to Respond to Medical Treatment}

Our experience has been that the great majority of attacks of ulcerative colitis can be terminated successfully by medical treatment. The medical management of a severe attack requires intensive hospital care, which must include certain basic general measures, such as control of water and electrolyte balance, blood transfusion, and maintenance of nutrition. In addition, specific therapeutic agents should be used to encourage rapid termination of the attack, and in our own hands the combined use of systemic prednisolone and topical hydrocortisone, applied by means of a rectal drip, has been the usual approach. Other agents such as anticholinergics-for example, propantheline bromide-and sulphasalazine (Salazopyrin) have occupied a secondary role. The regime which we have employed has already been described in detail (Truelove, 1962).

When medical treatment appears to be failing, colectomy is the orthodox treatment. If done as an emergency procedure this carries a high mortality rate even in the best hands, being 